\title{
Modifiable Behavioral Risk Factors and the Value of Lifetime Earnings Lost among US Citizens From 2000-2016
}

\author{
GJ Putzer, MD, PhD ${ }^{1,2}$ \\ J Jaramillo, PhD $^{3}$ \\ ${ }^{1}$ Lynn University, School of Business \\ ${ }^{2}$ University of Central Florida College of Medicine \\ ${ }^{3}$ Adelphi University, Robert Willumstad School of Business
}

\begin{abstract}
There has been a steady, long-term decline in mortality rates in the US. Yet, modifiable behavioral risk factors still appear responsible for approximately one million yearly premature deaths or $40 \%$ of the annual total mortalities in the United States. This study evaluated seven modifiable behavioral risk factors (tobacco smoking, misuse of alcohol, poor diet and physical inactivity, motor vehicle crashes, suicide, illicit use of drugs, and risky sexual behaviors) with respect to using the value of lifetime earnings lost (VLTEL) attributable to premature deaths. In this study, we estimated US annual deaths caused by modifiable behavioral risk factors for the period of years inclusive of 2000-2016 and it was stratified by age groups. Annual deaths per modifiable risk factor and age group were used to estimate trends on mortality. Potential economic cost of these deaths was calculated using mortality cost and expected death distribution. Finally, expected life tables were obtained using yearly mortality. We assessed the overall trends of the seven modifiable risk factors over the last 16 years in the US and found putatively more than 1 million premature mortalities. This study also showed VLTEL associated with premature mortalities to be almost $\$ 400$ billion on an annual basis. Smoking and obesity were the two most common risk factors. Illicit drug use and misuse of alcohol have been increasing quite rapidly over the last decade. There are several noteworthy trends in the data. Smoking is one modifiable risk factor that has been decreasing among US citizens. In contrast, several other risk factors, such as illicit use of drugs, have been increasing in both incidence and monetary costs. The premature deaths examined in this study are important from a public health and health management perspective because they represent potentially preventable loss of life.
\end{abstract}

\section{Introduction}

There has been a long-term secular decline in mortality rates in the United States due to treatment, prevention and behavioral change (Case, 2015; Cutler, 2006; Deaton, 2013; Lee, 1992). There are many available interventions that likely have contributed to this increase in longevity such as improvements in medical chronic disease diagnoses and treatments, public health preventive strategies, media and policy advocacy, environmental interventions, and an increased emphasis on healthy lifestyles (Molinari, 2004; McKenna, 2010; CDC, 2017; AHRQ, 2017; NCI, 2005; Remington, 2005). Nevertheless, despite these interventions and improvements, modifiable risk factors such as tobacco smoking, misuse of alcohol, poor diet and physical inactivity still appear to be responsible for approximately $40 \%$ of the total annual mortalities in the United States (McGinnis, 1993; Mokdad, 2004; Cohen, 2008). This represents more than one million deaths annually in the United States of which may at least be partially attributable to modifiable risk factors (Putzer, 2017, Putzer, 2015, Kenney, 2008).

Health spending in the United States has been steadily rising over the past several decades (Jaramillo, 2017; Martin, 2016). According to the Altarum Institute (2016), health spending reached $18.2 \%$ of gross domestic product in 2016. Health resources are valuable, yet finite and limited so there is an associated opportunity cost with using a resource and/or corresponding finances for one endeavor vis-à-vis another alternative endeavor. Thus, health policies that promote increased awareness and education regarding risk in a transparent fashion highlight the necessity to reduce premature mortality costs attributable to modifiable behavioral factors. Moreover, these policies, often, further encourage implementing additional cost-effective preventive measures. Consequently, reducing the number of individuals engaging in modifiable risk factors through enhanced awareness, education and policy presumably should have a tangible effect on improved health status, employee productivity and a more effective utilization of limited public health resources. 
In this study, we evaluated seven modifiable behavioral risk factors [tobacco smoking, misuse of alcohol, poor diet and physical inactivity which may lead to obesity (Lauby-Secretan, 2016), motor vehicle crashes, suicide, illicit use of drugs, and risky sexual behaviors which may lead to sexually transmitted infections] which presumably lead to premature mortalities and examined the associated amount of lifetime earnings lost (VLTEL). Thus, we used the VLTEL to approximate financial costs attributable to premature deaths. Moreover, we assessed the trends of these factors over the last 16 years in the United States.

\section{Methods}

Mortality data used in this research was obtained from the US Centers of Disease Control and Prevention (2018). Mortality data was disaggregated using the methodology used in Keeney (16) to obtain deaths causes by modifiable behavioral risk factors. Value of Life Time Earnings Lost (VLTEL) was estimated using Mortality Cost from the US Census Bureau (2012). This study uses 2009 mortality costs - the most recent published costs from the US Census Bureau. Life expectancies were calculated according to Chiang (1972).

In this study, we estimated US annual deaths caused by modifiable behavioral risk factors for the period of years inclusive of 2000-2016 and it was stratified by age groups. Annual deaths per modifiable risk factor and age group were used to estimate trends on mortality. Potential economic cost of these deaths was calculated using mortality cost and expected death distribution. Finally, expected life tables were obtained using yearly mortality.

\section{Results}

Mortality due to modifiable behavioral risk factors accounts for approximately $40 \%$ of total annual mortality in the United States. Table 1 shows the distribution of mortality between 2000 and 2016.

Table 1: Mortality (in thousands) in the United States

\begin{tabular}{|l|c|c|c|c|c|c|c|c|c|c|c|c|c|c|c|c|c|}
\hline \multicolumn{10}{|c|}{ Mortality in United States [000] } \\
\hline & $\mathbf{2 0 0 0}$ & $\mathbf{2 0 0 1}$ & $\mathbf{2 0 0 2}$ & $\mathbf{2 0 0 3}$ & $\mathbf{2 0 0 4}$ & $\mathbf{2 0 0 5}$ & $\mathbf{2 0 0 6}$ & $\mathbf{2 0 0 7}$ & $\mathbf{2 0 0 8}$ & $\mathbf{2 0 0 9}$ & $\mathbf{2 0 1 0}$ & $\mathbf{2 0 1 1}$ & $\mathbf{2 0 1 2}$ & $\mathbf{2 0 1 3}$ & $\mathbf{2 0 1 4}$ & $\mathbf{2 0 1 5}$ & $\mathbf{2 0 1 6}$ \\
\hline Total & 2403.0 & 2416.0 & 2443.0 & 2447.9 & 2397.3 & 2447.8 & 2426.0 & 2423.5 & 2471.8 & 2436.9 & 2468.3 & 2515.3 & 2543.1 & 2596.9 & 2626.3 & 2712.5 & 2744.1 \\
\hline Natural & 1360.6 & 1375.0 & 1392.7 & 1400.7 & 1372.2 & 1409.3 & 1404.7 & 1408.1 & 1447.0 & 1429.3 & 1454.8 & 1492.4 & 1512.0 & 1550.3 & 1570.8 & 1627.1 & 1649.1 \\
\hline Risk Factors & 1042.4 & 1041.0 & 1050.3 & 1047.2 & 1025.1 & 1038.5 & 1021.3 & 1015.4 & 1024.8 & 1007.6 & 1013.5 & 1022.9 & 1031.1 & 1046.5 & 1055.4 & 1085.4 & 1095.0 \\
\hline Percent & 43.38 & 43.09 & 42.99 & 42.78 & 42.76 & 42.43 & 42.10 & 41.90 & 41.46 & 41.35 & 41.06 & 40.67 & 40.54 & 40.30 & 40.19 & 40.02 & 39.91 \\
\hline
\end{tabular}

Table 2 summarizes mortality attributable to each modifiable behavioral risk factor during the period of years inclusive of $2000-2016$.

Table 2: Annual mortality (in thousands) of each modifiable behavioral risk factor

\begin{tabular}{|l|r|r|r|r|r|r|r|r|r|r|r|r|r|r|r|r|r|}
\hline \multicolumn{110}{|c|}{ Mortality to Modifiable Behavioral Risk Factors [000] } \\
\hline Age|Year & 2000 & 2001 & 2002 & 2003 & 2004 & 2005 & 2006 & 2007 & 2008 & 2009 & 2010 & 2011 & 2012 & 2013 & 2014 & 2015 & 2016 \\
\hline Smoking & 454.0 & 451.9 & 455.0 & 454.2 & 442.6 & 451.9 & 440.1 & 437.7 & 447.7 & 438.6 & 439.4 & 442.8 & 443.7 & 450.3 & 448.7 & 458.7 & 454.5 \\
\hline Obesity & 434.4 & 431.5 & 432.3 & 428.4 & 416.8 & 417.9 & 409.3 & 405.6 & 405.8 & 400.1 & 402.5 & 404.2 & 407.1 & 411.8 & 416.0 & 425.4 & 427.2 \\
\hline Illicit Drugs & 9.4 & 10.0 & 12.2 & 13.5 & 14.0 & 15.1 & 17.6 & 16.6 & 15.9 & 15.4 & 15.2 & 16.2 & 16.9 & 18.3 & 20.2 & 23.7 & 31.0 \\
\hline Alcohol Misuse & 56.6 & 57.7 & 58.4 & 59.2 & 59.0 & 60.3 & 60.1 & 61.0 & 62.7 & 63.0 & 65.5 & 67.6 & 69.4 & 71.7 & 74.1 & 77.7 & 79.5 \\
\hline STDs & 20.6 & 20.2 & 20.2 & 19.8 & 19.1 & 18.8 & 18.7 & 18.0 & 17.2 & 16.3 & 15.4 & 15.1 & 14.9 & 14.9 & 14.6 & 14.5 & 14.2 \\
\hline Accidents & 38.1 & 39.0 & 40.6 & 40.7 & 41.2 & 41.8 & 42.2 & 42.0 & 39.5 & 37.2 & 37.1 & 37.6 & 38.6 & 38.4 & 39.1 & 41.2 & 43.7 \\
\hline Suicide & 29.3 & 30.6 & 31.6 & 31.5 & 32.4 & 32.6 & 33.3 & 34.6 & 36.0 & 36.9 & 38.4 & 39.5 & 40.6 & 41.1 & 42.8 & 44.2 & 45.0 \\
\hline \multicolumn{1}{|c|}{ Total } & $1,042.4$ & $1,041.0$ & $1,050.3$ & $1,047.2$ & $1,025.1$ & $1,038.5$ & $1,021.3$ & $1,015.4$ & $1,024.8$ & $1,007.6$ & $1,013.5$ & $1,022.9$ & $1,031.1$ & $1,046.5$ & $1,055.4$ & $1,085.4$ & $1,095.0$ \\
\hline
\end{tabular}

Figure 1 shows mortality trends by behavioral risk factors (the $y$-axis represents the yearly mortality / 2000 mortality). Obesity and smoking mortality has remained stable over the last 16 years while there has been an important reduction in mortality due to STD's. 
On the other hand, there has been a large incremental increase in mortality due to illicit drug use. Notice that mortality due to illicit drugs has increased by more than $200 \%$ and the slope of the curve is increasing exponentially after the year 2012 .

Figure 1: Trends in modifiable behavioral risk factors. Y axis is (yearly mortality) / (2000 mortality)

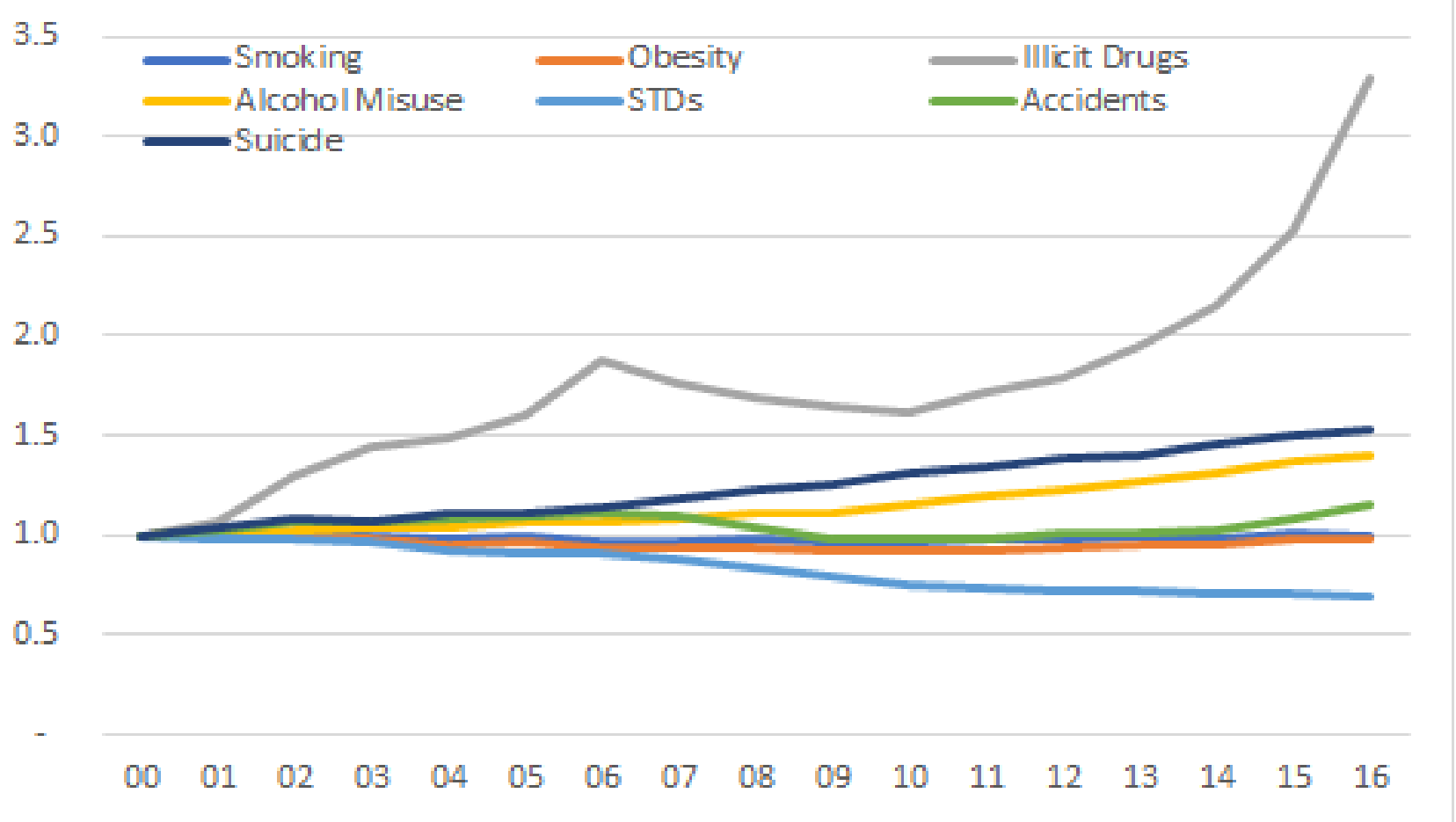

Table 3 shows total mortality by age groups. There has been an increase in mortality among the 15-24, $25-34$, and 55-64 age groups. There has been a decline among age group $35-44$ years of age.

Table 3: Annual mortality (in thousands) due to modifiable behavioral risk factors by age groups

\begin{tabular}{|c|r|r|r|r|r|r|r|r|r|r|r|r|r|r|r|r|r|}
\hline \multicolumn{10}{|c|}{ Mortality to Modifiable Behavioral Risk Factors [000] } \\
\hline Age|Year & $\mathbf{2 0 0 0}$ & $\mathbf{2 0 0 1}$ & $\mathbf{2 0 0 2}$ & $\mathbf{2 0 0 3}$ & $\mathbf{2 0 0 4}$ & $\mathbf{2 0 0 5}$ & $\mathbf{2 0 0 6}$ & $\mathbf{2 0 0 7}$ & $\mathbf{2 0 0 8}$ & $\mathbf{2 0 0 9}$ & $\mathbf{2 0 1 0}$ & $\mathbf{2 0 1 1}$ & $\mathbf{2 0 1 2}$ & $\mathbf{2 0 1 3}$ & $\mathbf{2 0 1 4}$ & $\mathbf{2 0 1 5}$ & $\mathbf{2 0 1 6}$ \\
\hline$<1$ & 1.1 & 1.0 & 1.0 & 1.0 & 1.0 & 1.0 & 1.0 & 1.0 & 1.0 & 0.9 & 0.8 & 0.8 & 0.8 & 0.8 & 0.8 & 0.8 & 0.8 \\
\hline $\mathbf{1 - 4}$ & 0.9 & 0.8 & 0.8 & 0.8 & 0.8 & 0.8 & 0.7 & 0.7 & 0.6 & 0.7 & 0.6 & 0.6 & 0.6 & 0.6 & 0.5 & 0.5 & 0.6 \\
\hline $\mathbf{5 - 1 4}$ & 1.9 & 1.8 & 1.7 & 1.7 & 1.7 & 1.6 & 1.4 & 1.3 & 1.2 & 1.1 & 1.1 & 1.1 & 1.1 & 1.2 & 1.2 & 1.2 & 1.3 \\
\hline $\mathbf{1 5 - 2 4}$ & 12.6 & 12.8 & 13.6 & 13.5 & 14.0 & 13.8 & 14.2 & 13.9 & 12.8 & 11.9 & 11.8 & 12.1 & 12.0 & 11.9 & 12.2 & 13.1 & 14.0 \\
\hline $\mathbf{2 5 - 3 4}$ & 17.7 & 17.8 & 17.9 & 17.7 & 17.7 & 17.7 & 18.4 & 18.2 & 17.7 & 17.2 & 17.6 & 18.4 & 19.1 & 19.6 & 20.7 & 22.8 & 26.2 \\
\hline $\mathbf{3 5 - 4 4}$ & 47.5 & 47.9 & 48.4 & 47.2 & 45.0 & 44.1 & 43.3 & 41.1 & 38.5 & 36.6 & 34.7 & 34.2 & 33.8 & 33.8 & 34.4 & 35.6 & 37.8 \\
\hline $\mathbf{4 5 - 5 4}$ & 88.5 & 91.7 & 94.5 & 96.4 & 97.3 & 99.9 & 101.3 & 100.7 & 100.8 & 100.1 & 98.7 & 97.6 & 95.9 & 93.6 & 92.1 & 90.8 & 89.7 \\
\hline $\mathbf{5 5 - 6 4}$ & 140.6 & 141.3 & 146.3 & 150.4 & 150.8 & 155.7 & 158.2 & 160.6 & 163.7 & 166.4 & 170.5 & 176.5 & 179.0 & 182.6 & 187.4 & 192.2 & 195.4 \\
\hline Subtotal & 310.8 & 315 & 324.1 & 328.6 & 328.3 & 334.6 & 338.7 & 337.6 & 336.3 & 334.9 & 335.9 & 341.2 & 342.3 & 344 & 349.2 & 356.9 & 365.8 \\
\hline $\mathbf{6 5 - 7 4}$ & 218.0 & 212.4 & 208.2 & 203.1 & 196.8 & 195.8 & 191.0 & 190.3 & 195.6 & 194.7 & 196.7 & 199.2 & 206.8 & 215.0 & 220.7 & 229.7 & 234.5 \\
\hline $75-84$ & 291.5 & 291.1 & 292.7 & 289.9 & 281.1 & 281.4 & 270.7 & 264.3 & 262.5 & 252.4 & 249.2 & 247.1 & 243.5 & 244.2 & 242.6 & 246.0 & 244.6 \\
\hline$>85$ & 222.1 & 222.6 & 225.4 & 225.6 & 218.9 & 226.8 & 220.9 & 223.1 & 230.4 & 225.5 & 231.7 & 235.5 & 238.5 & 243.3 & 242.9 & 252.8 & 250.1 \\
\hline Total & 1042.4 & 1041.0 & 1050.3 & 1047.2 & 1025.1 & 1038.5 & 1021.3 & 1015.4 & 1024.8 & 1007.6 & 1013.5 & 1022.9 & 1031.1 & 1046.5 & 1055.4 & 1085.4 & 1095.0 \\
\hline
\end{tabular}


Figure 2 shows mortality trends for varying age groups. Notice that $y$-axis is yearly mortality scaled with respect to year 2000. Values above 1 (i.e., the red line) indicate an increase in mortality; whereas, data values below the red line indicate a reduction.

Figure 2: Annual mortality due to modifiable behavioral risk factors trends by age. $Y$-axis is (yearly mortality) / (2000 mortality)

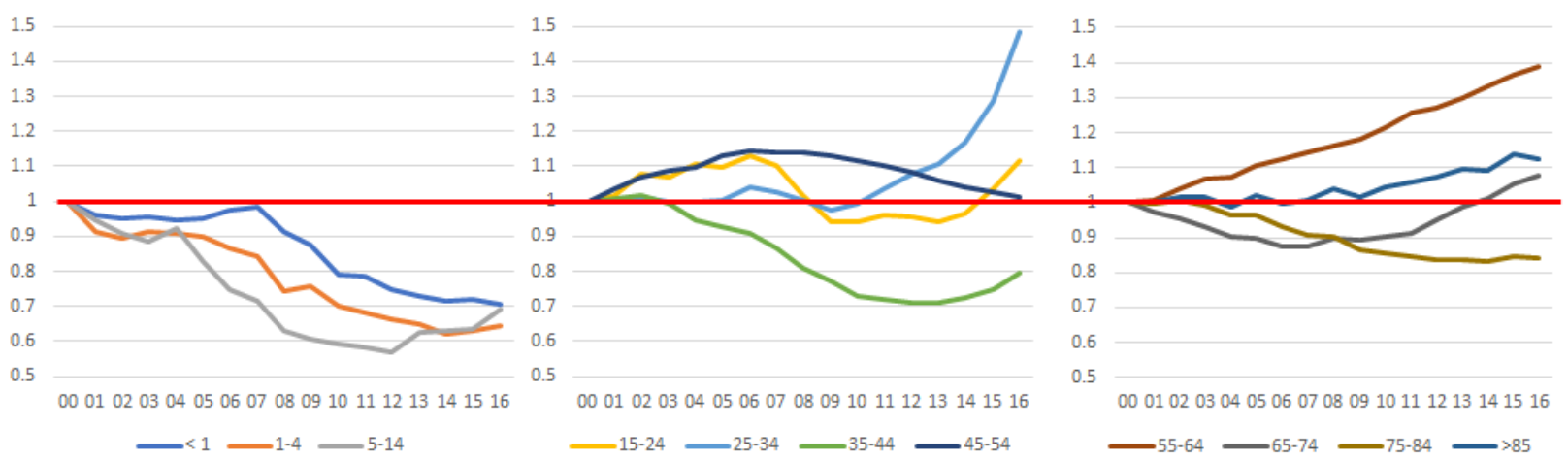

The life expectancy of an average American born in 2016 at the moment of birth was 78.6 years. Commonly, life expectancy is expressed as expected additional years of life after the current age. That is, a 30 year old, average 2016 American was expected to live for another 50.0 years. It is also possible to calculate life expectancies without including mortality due to behavioral risk factors. Figure 3 shows expected life for the population and for a population that "avoids" mortality due to behavioral risk factors. Notice that life expectancy would increase from 78.6 to 83.5 years at the moment of birth. Figure 3, in the left hand sided chart, the graph shows the difference in expected additional years at each age between both groups.

Figure 3: Expected years of life
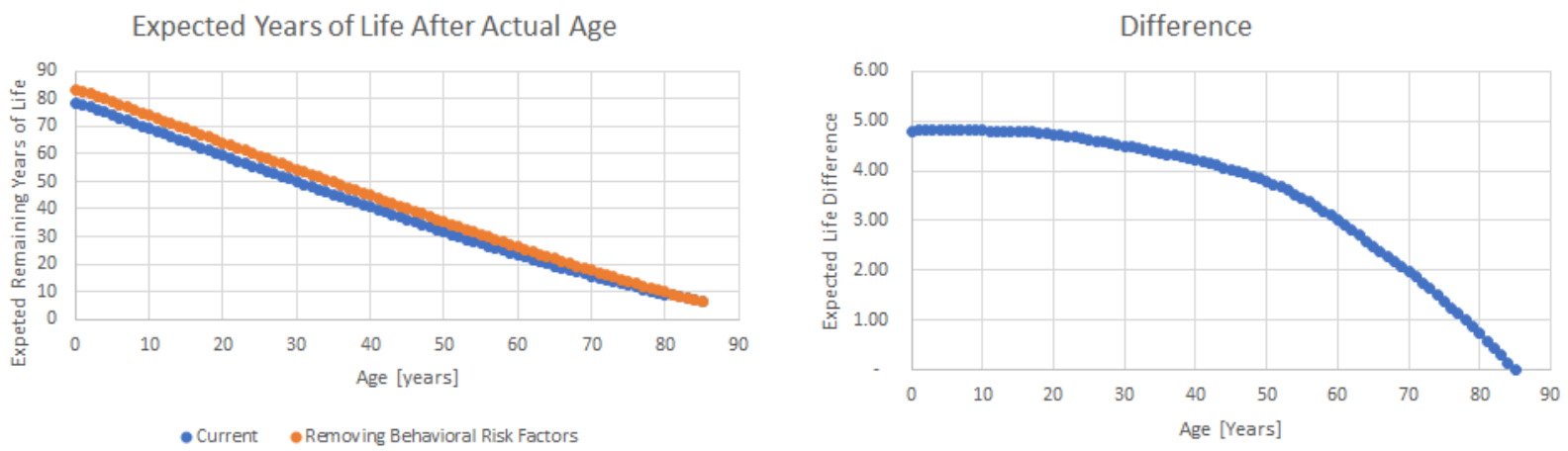

Table 4 shows VLTEL estimation using mortality costs from 2009. Mortality above 75 years old was removed from VLTEL. The largest contributor to VLTEL is the $45-64$ age cohort. Notice that the highest cost per single death is for the age group $15-24$.

Table 4: Estimated Mortality Cost Due to Behavioral Risk Factor
\begin{tabular}{|c|r|r|r|} 
Age Group & $\begin{array}{c}\text { Mortality } \\
{[\text { [O00] }}\end{array}$ & $\begin{array}{c}\text { Cost per } \\
\text { Death [000] }\end{array}$ & $\begin{array}{c}\text { VLTEL } \\
\text { [Millions] }\end{array}$ \\
\hline$<\mathbf{5}$ & 1.3 & $1,154.82$ & $\mathbf{1 , 5 1 3 . 5}$ \\
\hline $\mathbf{5 - 1 4}$ & 1.3 & $1,457.17$ & $\mathbf{1 , 8 9 1 . 8}$ \\
\hline $\mathbf{1 5 - 2 4}$ & 14.0 & $1,732.51$ & $\mathbf{2 4 , 3 1 3 . 0}$ \\
\hline $\mathbf{2 5 - 4 4}$ & 64.0 & $1,370.20$ & $\mathbf{8 7 , 7 1 5 . 3}$ \\
\hline $\mathbf{4 5 - 6 4}$ & 430.0 & 634.99 & $\mathbf{2 7 3 , 0 1 5 . 1}$ \\
\hline $\mathbf{6 5 - 7 5}$ & 250.1 & 18.96 & $\mathbf{4 , 7 4 2 . 2}$ \\
\hline Total & 760.7 & & $\mathbf{3 9 3 , 1 9 0 . 9}$ \\
\hline
\end{tabular}




\section{Discussion}

There are several noteworthy trends shown in this study. The annual mortality attributable to modifiable behavioral risk factors has changed when categorized by age since the turn of the century. There has been an overall gradual decline in mortality due to behavioral risk factors for ages 15 and younger (notwithstanding year 2016).

In contrast, the data indicates a strong increase in age group 24-35 (approximately a 50\% increase with respect to year 2000) and among the 55-64 (about 40\% increase with respect to year 2000) age cohort in premature mortalities due to behavioral risk factors. The age group $15-24$ also shows a mortality increase, but it does not begin until the year 2014 .

The overall percentage of mortalities $(39.91 \%$ in 2016) associated with modifiable behavioral risk factors has been modestly declining over the last few decades, albeit it at a slow pace. Nevertheless, as shown in Table 1, the gross aggregate number of avoidable deaths is still increasing and represents an important percentage of total annual mortalities. Smoking and obesity continue to account for the majority of overall annual mortalities. Smoking and obesity are the most influential factors after age 45. According to the National Cancer Institute (2017), the overall number of cancer mortality rates, including lung cancer which is predominantly acquired from smoking, has been decreasing. Our study data shows that premature deaths associated with smoking have been declining; whereas, the general trend of mortality attributable to obesity continues to increase.

In contrast, children and teens are principally affected by accidents. For young adults - accidents, suicide and illicit drugs - are the principal behavioral factors leading to premature deaths. Each of these behavioral risk factors has been showing an increasing trend since year 2000. The mortality attributable to illicit drugs has increased by more than $200 \%$ presumably as a consequence of the opioid epidemic. Similarly, alcohol misuse and suicide are showing an increasing trend over the last few decades. Despite their relative low mortality overall rates, at least in comparison with the two most common modifiable risk factors of obesity and smoking, the mortality associated with alcohol misuse and illicit drug use has been increasing quite rapidly.

According to the National Health Interview Surveys (2017) spanning 1997-2014, there has been an upward trend in drinking among adults over 60. According to recent studies (Case, 2017; Case 2015) mortality from alcohol as well as illicit drug use has been on the rise among certain ethnicities. The reasons are complex, multifactorial and will require extensive research to more clearly elucidate. For example, as reported by the Brookings Institution (2017), the increased mortality is linked to resources, especially family income; and a long-standing evolution of "cumulative disadvantage for those with less than a college degree" (Case, 2017, page 3). Our data corroborates this finding as illicit drug use has been increasing especially within age groups 55-64 and 65 - 74 (increase of greater than 1,000 percent); whereas, for other age cohorts the increased range is between $100 \%$ and $300 \%$. Similarly, alcohol misuse shows a strong increase with larger percentages for age groups $55-64$, as well as the $25-35$ age cohort. There has also been an increase among the age group of $15-24$, but it is not showing the exponential behavior of the other two age cohorts.

There are several limitations associated with this study. First, the accuracy of the mortalities recorded on death certificates can vary by underlying cause (Maudsley, 1996). Moreover, conducting analyses using underlying causes of death categories may underestimate the burden for selected contributing causes of death listed on the mortality certificate (Redelings, 2006). An example would be obesity which can presumably increase the risk of cancer (Lauby-Secretan, 2016), and/or heart disease. There are also methodological limitations involved with extrapolating life expectancies based upon behavioral risk factors. Moreover, it is difficult to ascertain the contribution or actual attributable effects of imprudent lifestyle or behaviors on premature deaths. There are many confounding variables that may affect these relationships. Mortality records are an important data source for assessing a population because they include the whole population with corresponding information pertinent to the contributing causes of death. Yet, cause-specific mortality is ordinarily reported using traditional epidemiologic measures, (i.e., counts and rates), that are heavily influenced by mortalities among older citizens (Putzer, 2016; Aragon, 2008). Thus, for most causes, these conventional measures are not very sensitive to mortalities occurring among younger individuals, which presumably are more likely to be premature and/or preventable deaths. The premature deaths examined in this study are important from a public health and health policy perspective because they represent possible preventable loss of life. A challenge is how to reverse the trends and to reduce the number and rate of premature deaths due to behavioral risk factors. Naturally, prevention is an area that is often mentioned to reduce behavioral risk factors. 
Preventive measures and services may provide an area that offers opportunities to improve health and save money simultaneously. There is evidence that suggests prevention does save money and improve health. For example, there is evidence from the U.S. Preventive Task Force which identified measures - such as counseling adults to stop smoking and screening for certain cancers - that reduced mortality and lower costs (Maciosek, 2006). Yet, other studies have concluded that preventive measures can also lead to higher costs unless these measures incorporate factors such as the targeting a higher-risk population (Russell, 2007; Cohen, 2008). Thus, incorporating preventive measures and treatments which are most effective is important, but equally important is providing intensified education to citizens and creating health policies that incentivize and reward medical protocols and practice dedicated toward an enhanced emphasis on reducing behavioral risk factors.

\section{References}

Case A, Deaton A. 2015. Rising Morbidity and mortality in midlife among white non-Hispanic Americans in the $21^{\text {st }}$ century. Proceedings of the National Academy of Sciences of the USA, 112(49). doi: 10.1073/pnas.1518393112.

Cutler DM, Deaton A, Lieras-Muney A. 2006. The determinants of mortality. J Econ Perspectives, 20(3): 97-120.

Deaton A. 2013. The Great Escape: Health, Wealth, and the Origins of Inequality. Princeton University Press, Princeton, NJ.

Lee RD, Carter LR. 1992. Modeling and forecasting U.S. mortality. J Am Stat Assoc, 87(419): 659-671.

Molinari NAM. 2004. The Effect of Health Care on Population Health. The Lancet, 364: 1558-1560.

McKenna M, Collins J. Current Issues and Challenges in Chronic Disease Control [Chapter 1]. In: Remington PL, Brownson R, Wegner MV, eds. Chronic Disease Epidemiology and Control. ${ }^{\text {rd }}$ edition. Washington, DC: American Public Health Association; 2010: 1-16.

Centers for Disease Control. The Guide to Community Preventive Services. Available at http://www.thecommunityguide.org/index.html

Agency for Healthcare Research and Quality. National Guideline Clearinghouse Available at http://www.guideline.gov/

National Cancer Institute. Monograph 16: ASSIST. Shaping the Future of Tobacco Prevention and Control. Bethesda, MD: US Department of Health and Human Services, National Institutes of Health, National Cancer Institute; 2005.

Remington PL, Houston CA, Cook LC. Media interventions to promote tobacco control policies. In: Monograph 16: ASSIST. Shaping the Future of Tobacco Prevention and Control. Bethesda, MD: US Department of Health and Human Services, National Institutes of Health, National Cancer Institute; 2005:119-66.

McGinnis JM, Foege WH. 1993. Actual Causes of death in the US. Journal of the American Medical Association, 270: 2207-2212.

Mokdad AH, Marks JS, Stroup DF, Gerberding JL. 2004. Actual causes of death in the United States, 2000. Journal of the American Medical Association, 291:1238-1245.

Cohen JT, Neumann PJ, Weinstein MC. 2008. Does Preventive Care Save Money? Health Economics and the Presidential Candidates. New England Journal of Medicine, 358:661-663.

Putzer GJ, Jaramillo J. 2017. Trends in Behavioral Risk Factors Resulting in Premature Death in US from 20002015. International Journal of Research in Business Studies and Management, 4(4): 8-12.

Putzer GJ, Jaramillo J. 2015. Premature Mortality Costs Associated with Lifestyle Factors among US Citizens. Review of Public Administration Management, 3:177. doi 10.4172/2315-7844.100017

Keeney R. 2008. Personal Decisions are the Leading Causes of Death. Operations Research, 56:1335-1347.

Jaramillo J, Putzer G. 2017. Using Data Envelope Analysis to Examine US State Health Efficiencies over 20082015. Global Journal of Human Social Science, XVII (II): 7-14.

Martin AB, Hartman M, Benson J, et al. 2016. National Health Spending in 2014: Faster Growth Driven by Coverage Expansion and Prescription Drug Spending. Health Affairs, 35(1): 150-160.

Altarum Institute. Accessed September 9, 2016. http://altarum.org/sites/default/files/uploaded-related-files/CSHSSpending-Brief_September_2016.pdf

Lauby-Secretan B, Scoccianti C, Loomis D, et al. 2016. Body Fatness and Cancer -Viewpoint of the IARC Working Group. New England Journal of Medicine, 375:794-798.

Center for Disease Control and Prevention. Accessed May 15, 2018. https://wonder.cdc.gov/mcd-icd10.html 
Statistical Abstract of the United States: 2012, Section 2. United States Census Bureau. Available at: https://www.census.gov/library/publications/2011/compendia/statab/131ed.html

Chiang C. 1972. On Constructing Current Life Tables Journal of the American Statistical Association. 67 (339): 538-554. doi 10.2307/2284435.

Jemal A, Ward EM, Johnson CJ, et al. 2017. Annual Report to the Nation on the Status of Cancer, 1975-2014, Featuring Survival. J Natl Cancer Institute, 109(9): djx030.

Breslow RA, Castle IP, Chen CM, et al. Trends in Alcohol Consumption among Older Americans: National Health Interview Surveys, 1997-2014. 2017. Alcoholism Clinical and Experimental Research. doi 10.1111.acer.13365.

Case A, Deaton A. 2017. Mortality and morbidity in the $21^{\text {st }}$ century. Brookings Papers on Economic Activity. Accessed April 3, 2017. https://www.brookings.edu/wp-content/uploads/2017/03/6_casedeaton.pdf

Maudsley G, Williams EM. Inaccuracy in death certification-where are we now? 1996. J Public Health Med, 18:59-66.

Redelings MD, Sorvillo F, Simon P. 2006. A comparison of underlying cause and multiple causes of death: US vital statistics, 2000-2001. Epidemiology, 17:100-103. doi 10.1097/01.ede.0000187177.96138.c6.

Putzer G, Jaramillo J. 2016. Using Data Envelope Analysis to Assess the Efficiency of the US Health System. Journal of Socialomics, 5:4. doi 10.4172/2167-0358.1000183

Aragon TJ, Lichtensztajn DY, Katcher B, et al. 2008. Calculating expected years of life lost for assessing local ethnic disparities in causes of premature death. BMC Public Health, 8:116. doi 10.1186/1471-2458-8-116.

Maciosek MV, Coffield AB, Edwards NM, Flottemesch TJ, Goodman MJ, Solberg LI. 2006. Priorities among effective clinical preventive services: results of a systematic review and analysis. Am J Prev Med, 31:5261.

Russell LB. Prevention's potential for slowing the growth of medical spending. Washington, DC: National Coalition on Health Care, October 2007. Accessed March 22, 2017. http://www.nchc.org/nchc_report.pdf. 